\title{
Níveis de Energia Digestível para Suínos dos 30 aos 60 kg Mantidos em Ambiente de Conforto Térmico 1
}

\section{Sandra Lúcia da Silva Tavares ${ }^{2}$, Juarez Lopes Donzele ${ }^{3}$, Rita Flávia Miranda de Oliveira ${ }^{3}$, Aloízio Soares Ferreira ${ }^{3}$}

\begin{abstract}
RESUMO - Dois experimentos foram conduzidos para avaliar os efeitos de níveis de energia digestível (ED) sobre desempenho e composição de ganho de carcaça. Foram usados cinqüenta leitoas e 50 machos castrados, mestiços, dos 30 aos $60 \mathrm{~kg}$ PV mantidos em ambiente de termoneutralidade. O delineamento usado foi o de blocos ao acaso, com cinco tratamentos $(3100,3250,3400,3550$ e $3700 \mathrm{kcal} \mathrm{ED} / \mathrm{kg}$ de dieta), cinco repetições e dois animais por unidade experimental. No experimento com leitoas, o nível de ED da ração não influenciou o ganho de peso diário, o consumo de ração e o consumo de proteína. A conversão alimentar melhorou e o consumo de ED aumentou, linearmente, em função dos níveis crescentes de ED da dieta. No experimento com machos castrados, o nível de ED da ração não influenciou o ganho de peso diário dos animais, enquanto o consumo de ração e proteína decresceu linearmente. A conversão alimentar melhorou linearmente e o consumo de ED não variou em função dos níveis crescentes de ED da dieta. O nível de ED da dieta não influenciou a taxa de deposição de proteína, mas a taxa de deposição de gordura aumentou quadraticamente para as leitoas e linearmente para os machos. Os melhores resultados de desempenho com machos castrados foram obtidos com o nível de $3582 \mathrm{kcal}$ de ED e, no experimento com leitoas, o nível de $3700 \mathrm{kcal}$ de $\mathrm{ED} / \mathrm{kg}$ proporcionou os melhores resultados de conversão alimentar.
\end{abstract}

Palavras-chave: nível de energia digestível, leitoas, machos castrados, ambiente termoneutro, desempenho, composição de carcaça

\section{Digestible Energy Levels for Swines from 30 to $60 \mathrm{~kg}$ Maintained in a Thermoneutral Environment}

\begin{abstract}
Two experiments were conducted to evaluate the effects of digestible energy (DE) levels on performance and carcass gain composition. Fifty crossbred gilts and 50 crossbred barrows, from 30 to $60 \mathrm{~kg}$, maintained in a thermoneutral environment, were used. The experimental design was a randomized blocks with five treatments (3100, 3250, 3400, 3550, and $3700 \mathrm{kcal}$ de DE/kg of diet), five replicates and two animals per experimental unit. In the experiment with gilts the DE level did not influence daily weight gain, feed intake and protein intake of animals. Feed:gain ratio and DE intake improved linearly on the increasing dietary DE levels. In the experiment with barrows, the DE level did not influence the daily weight gain, while the feed and protein intake linearly decreased. The feed:gain ratio linearly improved and the DE intake did not vary on the increasing dietary DE levels. The dietary DE levels did not influence the protein deposition rate, but the fat deposition rate increased in a quadratic way in the gilts and linearly for the barrows. The best performanceresults for barrows were obtained with the level of $3582 \mathrm{kcal}$ DE, and for gilts, the best results of feed:gain ratio was obtained for $3700 \mathrm{kcal}$ of $\mathrm{DE} / \mathrm{kg}$.
\end{abstract}

Key Words: digestible energy level, gilt, barrows, thermoneutral environment, performance, carcass composition

\section{Introdução}

O ambiente no qual o suíno é mantido influencia o seu desempenho, por influir, entre outros fatores, no consumo voluntário de alimentos.

Sabe-se que a faixa de temperatura ideal para o desenvolvimento animal éa zona de termoneutralidade, na qual a produção de calor não é influenciada pelas condições climáticas, ocorrendo a uma taxa dependente do nível de alimentação ou do peso animal (VERSTENGEN e CLOSE, 1994). Dessa forma, o aumento na densidade energética da dieta resulta em redução no consumo de alimentos para manter consumo constante de energia.

Trabalhos conduzidos com suínos em fase de crescimento e terminação (STAHLY e CROMWELL, 1979; DIVIDICH e NOBLET, 1986; e OLIVEIRA, 1996) para avaliar o efeito de dietas com diferentes níveis de energia digestível têm revelado que dietas com maiores níveis de energia resultam em redução no consumo de alimentos e melhoria na conversão alimentar dos animais mantidos em ambiente termoneutro. NOBLET et al. (1985), fornecendo 
ração para suínos com alto e baixo nível de energia, observaram que na faixa termoneutra a dieta de baixa energia está associada à maior produção de calor.

$A$ adição de gordura às dietas de suínos em crescimento e terminação geralmente melhora a eficiência alimentar, aumenta ou não o ganho de peso e influencia medidas de carcaça (SPEER, 1991). O consumo de alimentos por suínos recebendo dieta com alta concentração de energia contribui para maior deposição de gordura na carcaça.

Pesquisas têm demonstrado que a maior concentração de energia da dieta obtida pela inclusão de gordura apresenta melhores resultados de eficiência de utilização de energia e maior gordura corporal pelos suínos submetidos a ambiente de termoneutralidade (STAHLY e CROMWELL, 1979; SCHENCK et al., 1992; e OLIVEIRA et al., 1996).

Este trabalho foi conduzido com o objetivo de avaliar os efeitos de rações isoprotéicas com diferentes níveis de energia digestível sobre o desempenho e a composição de ganho da carcaça de leitoas e machos castrados dos 30 aos $60 \mathrm{~kg}$ de peso, mantidos em ambiente termoneutro.

\section{Material e Métodos}

Os experimentos foram conduzidos no Setor de Suinocultura do Departamento de Zootecnia do Centro de Ciências Agrárias da Universidade Federal de Viçosa, em Viçosa, MG.

\section{Experimento 1}

Utilizaram-se 50 leitoas, mestiças, com peso inicial médio de $30,11 \pm 1,79 \mathrm{~kg}$, distribuídas em delineamento experimental de blocos ao acaso com cinco tratamentos $(3100,3250,3400,3550$ e $3700 \mathrm{kcal}$ de energia digestível/kg de dieta), cinco repetições e dois animais por unidade experimental. Na formação dos blocos, foi adotado o critério de peso inicial e parentesco dos animais.

As condições térmicas da sala durante o período experimental foram $21,39 \pm 1,00^{\circ} \mathrm{C}$ de temperatura do ar, 75,8 $\pm 6,56 \%$ de umidade relativa, 21,74 \pm $0,91^{\circ} \mathrm{C}$ de temperatura de globo negro e $69,02 \pm 1,09$ de Índice de Temperatura de Globo e Umidade.

A temperatura média interna da sala foi mantida por meio de dois aparelhos de ar-condicionado ligados a um termostato regulado para a temperatura de $22^{\circ} \mathrm{C}$ e por um conjunto de seis aquecedores, tipo campânulas de resistência, ligados a um termostato regulado para a temperatura de $19^{\circ} \mathrm{C}$. Os termostatos e os equipamentos de medição ambiental (termômetros de bulbo seco e bulbo úmido, de máxima e mínima e de globo negro) foram instalados em uma gaiola vazia no centro da sala a uma altura correspondente à do animal. As leituras dos instrumentos foram realizadas às 8 e $16 \mathrm{~h}$.

Grupos de dois animais foram alojados em gaiolas metálicas, suspensas, com piso e laterais ripados, dotadas de comedouros semi-automáticos e bebedouro tipo chupeta, localizadas em sala de alvenaria com piso de concreto e forro de madeira rebaixada, dotada de janelões de vidro tipo basculante.

As dietas experimentais (Tabela 1) foram formuladas de forma a atender as necessidades nutricionais, de vitaminas e minerais dos animais, com o nível de proteína bruta $10 \%$ acima do recomendado por ROSTAGNO et al. (1992) e os níveis de energia digestível obtidos por intermédio de alterações das concentrações de óleo, amido e areia lavada, e fornecidas à vontade.

As sobras de ração foram pesadas semanalmente e os animais no início e ao final do experimento, quando atingiram, em média, $60,85 \pm 4,40 \mathrm{~kg}$, para determinação do ganho de peso, consumo de dieta e conversão alimentar.

No final do experimento, após jejum de 24 horas, os animais de cada tratamento foram abatidos, por sangramento, depilados e eviscerados. Após pesagem, as carcaças foram divididas por meio de corte longitudinal e as metades direitas das carcaças foram trituradas, por 15 minutos, em "cutter" comercial de 30 HP e 1775 revoluções por minuto. Após a homogeneização, retiraram-se amostras que foram estocadas em freezer. Um grupo adicional de cinco leitoas, com peso médio de $30,34 \pm 0,94 \mathrm{~kg}$, foi abatido para determinação da composição da carcaça no início do experimento.

As amostras de carcaça pré-secas em estufa de ventilação forçada, $\mathrm{a} \pm 60^{\circ} \mathrm{C}$ por 96 horas, foram prédesengorduradas pelo método a quente no extrator tipo "soxhlet", por cinco horas, para posteriores moagem e análises de proteína e gordura das amostras conforme recomendações de SILVA (1990).

As taxas de deposição de gordura e proteína nas carcaças foram calculadas comparando-se as composições das carcaças das leitoas no início com as do final do experimento.

As análises estatísticas das variáveis de desempenho e taxas de deposição de gordura e proteína nas carcaças foram realizadas utilizando-se o programa ANOVAG, contido no pacote computacional SAEG 
Rev. bras. zootec.

Tabela 1 - Composição das rações experimentais (\%)

Table 1 - Composition of experimental diets

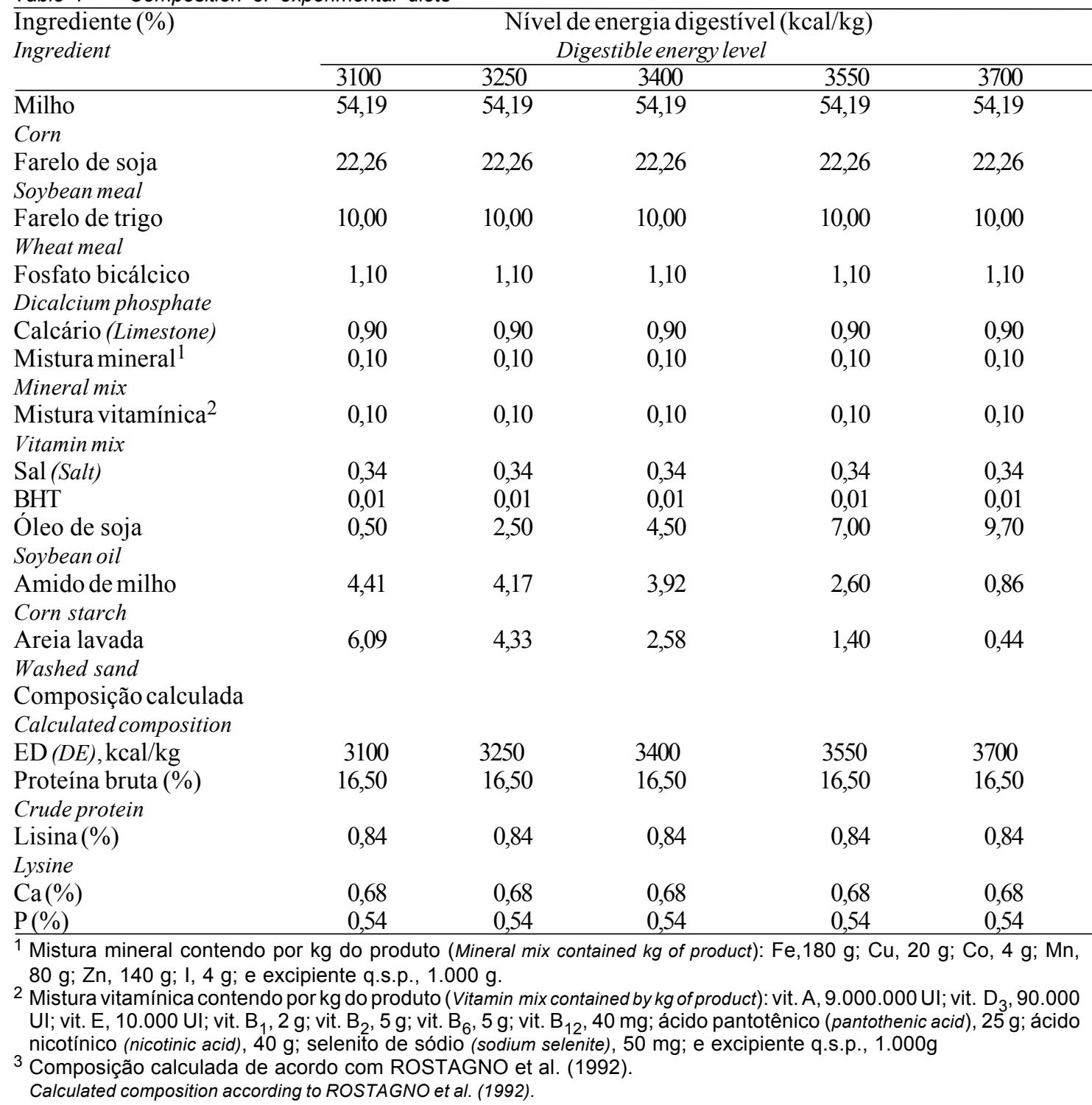

(Sistema para Análises Estatísticas e Genéticas) e seguindo o modelo estatístico:

$$
Y_{i j}=\mu+E_{i}+B_{j}+e_{i j}
$$

em que

$\mathrm{Y}_{\mathrm{ij}}=$ ganho peso, ou consumo de ração, ou conversão alimentar ou taxas de deposição de proteína e gordura referentes ao nível de energia i no bloco j;

$\mathrm{m}$ = média geral da característica;

$\mathrm{E}_{\mathrm{i}}=$ efeito do nível de energia $\mathrm{i}$;

$\mathrm{B}_{\mathrm{j}}=$ efeito do bloco $\mathrm{j}$; e

$\mathrm{e}_{\mathrm{ij}}=$ erro aleatório associado a cada observação. Experimento 2

Utilizaram-se 50 machos castrados, mestiços, com peso inicial médio de $30,47 \pm 2,08 \mathrm{~kg}$ e peso final médio de $60,1+3,91 \mathrm{~kg}$, distribuídos em delineamento experimental de blocos ao acaso com cinco tratamentos $(3100,3250,3400,3550$ e $3700 \mathrm{kcal}$ de energia digestível/kg de dieta), cinco repetições e dois animais por unidade experimental. $\mathrm{Na}$ formação dos blocos, foi adotado o critério de peso inicial e parentesco dos animais.

As condições térmicas da sala durante o período experimental foram de $21,33 \pm 1,04^{\circ} \mathrm{C}$ de temperatura do ar, $61,8 \pm 2,64 \%$ de umidade relativa, $21,73 \pm 0,97^{\circ} \mathrm{C}$ de temperatura de globo negro e 68,92 $\pm 1,19$ de Índice de Temperatura de Globo e Umidade.

Os procedimentos de controle ambiental, instalações, dieta, determinação das medidas de desempenho e composição de carcaça, amostragem, análise química e análise e modelo estatístico foram idênticos aos do experimento 1 . 


\section{Resultados e Discussão}

\section{Experimento 1}

Os resultados de desempenho, consumos de energia e proteína e taxas de deposição de gordura e proteína de leitoas são apresentados na Tabela 2 . Não se observou efeito dos níveis de energia sobre o ganho de peso diário (GPD) dos animais. Estes resultados foram semelhantes aos observados por STAHLY e CROMWELL (1979) e OLIVEIRA (1996), que não verificaram efeito da adição de $5 \%$ de gordura à dieta de suínos em terminação e crescimento e da dieta com níveis crescentes de energia digestível de leitoas, respectivamente, sobre o ganho de peso dos animais mantidos em ambiente de conforto térmico.

Embora o GPD não tenha sido influenciado significativamente, constatou-se que os animais que receberam a ração com 3100 kcal de ED apresentaram redução nãosignificativa de 3,4 a $8,23 \%$ no GPD, enquanto para os que receberam o tratamento com $3550 \mathrm{kcal}$ de ED o GPD aumentou, não significativamente, em até $8,96 \%$ em relação aos demais tratamentos. Estas variações nãosignificativas no GPD dos animais, provavelmente, ocorreram em razão das verificadas no consumo de energia digestível entre os tratamentos.

Com relação ao consumo de ração diário (CR), não se observou variação em razão do aumento no nível de ED, evidenciando que os animais não ajustaram os seus consumos pela densidade energética da ração. Estes resultados são semelhantes aos obtidos por STAHLY e CROMWELL (1979) e SCHENCK et al. (1992), ao avaliarem o efeito da adição de 5\% de gordura à ração para suínos dos 24 aos $60 \mathrm{~kg}$ e dos 8 aos $30 \mathrm{~kg}$ de peso, mantidos em ambiente termoneutro, respectivamente.

O nível de ED da dieta influenciou $(\mathrm{P}<0,02)$ a conversão alimentar (CA), que melhorou de forma linear segundo a equação $\hat{\mathrm{Y}}=3,958-0,0044 \mathrm{X}$ (Figura 1). A melhoria observada na CA dos animais pode ser atribuída ao provável aumento gradativo da energia líquida das rações, ocorrido em razão da redução do incremento calórico, devido à inclusão de níveis crescentes de óleo de soja. Estes resultados estão coerentes com os obtidos por STAHLY e CROMWELL (1979) e OLIVEIRA (1996), que constataram melhoria no CA de suínos, mantidos em ambiente termoneutro, em razão do nível de ED da ração, e com o relato de PETTIGREW e MOSER (1991), de que a adição de gordura às rações melhora a eficiência de utilização do alimento pelos suínos dos 20 aos $100 \mathrm{~kg}$.

Embora o CR não tenha variado significamente, o consumo de energia diário (CED) aumentou $(\mathrm{P}<0,02)$ de forma linear, conforme a equação $\hat{\mathrm{Y}}=2450,41+$ 1,24685X, em razão do aumento do nível de ED da

Tabela 2 - Desempenho, consumo de energia digestível e proteína e taxa de deposição de proteína (TDP) e gordura (TDG) de leitoas dos 30 aos $60 \mathrm{~kg}$ de peso consumindo rações com níveis crescentes de energia digestível sob condição de termoneutralidade

Table 2 - Performance, intake of digestible energy and protein, and deposition rate of protein (PDR) and fat (FDR) in gilts from 30 to $60 \mathrm{~kg}$ fed diets with increasing levels of energy in a thermoneutral environment

\begin{tabular}{|c|c|c|c|c|c|c|}
\hline \multirow[t]{2}{*}{ Item } & \multicolumn{5}{|c|}{$\begin{array}{l}\text { Nível de energia digestível ( } \mathrm{kcal} / \mathrm{kg}) \\
\text { Digestible energy level }\end{array}$} & \multirow[t]{2}{*}{$\begin{array}{l}\mathrm{CV} \\
(\%)\end{array}$} \\
\hline & 3100 & 3250 & 3400 & 3550 & 3700 & \\
\hline Ganho de peso (g/dia) & 770 & 811 & 797 & 839 & 801 & 6,1 \\
\hline Weight gain & & & & & & \\
\hline $\begin{array}{l}\text { Consumo de ração (g/dia) } \\
\text { Feed intake }\end{array}$ & 2017 & 2015 & 1946 & 2009 & 1864 & 6,4 \\
\hline $\begin{array}{l}\text { Conversão alimentar } \\
\text { Feed:gain ratio }\end{array}$ & 2,62 & 2,48 & 2,44 & 2,40 & 2,32 & 6,7 \\
\hline $\begin{array}{l}\text { Consumo de } \mathrm{ED}(\mathrm{kcal} / \mathrm{dia})^{1} \\
\text { DE intake }(k c a l / d a y)\end{array}$ & 6254 & 6548 & 6617 & 7133 & 6897 & 6,4 \\
\hline $\begin{array}{l}\text { Consumo de proteína }(\mathrm{g} / \mathrm{dia})^{1} \\
\text { Protein intake (g/day) } \\
\text { Taxas de deposição na carcaça } \\
\text { Carcass deposition rate }\end{array}$ & 333 & 332 & 321 & 332 & 308 & 6,4 \\
\hline $\begin{array}{l}\text { Proteína (g/dia) } \\
\text { Protein }\end{array}$ & 96,42 & 91,49 & 94,47 & 92,11 & 89,85 & 14,0 \\
\hline $\begin{array}{l}\operatorname{Gordura}^{2}(\mathrm{~g} / \mathrm{dia}) \\
\text { Fat }\end{array}$ & 157,44 & 199,58 & 218,43 & 236,18 & 227,75 & 17,1 \\
\hline
\end{tabular}




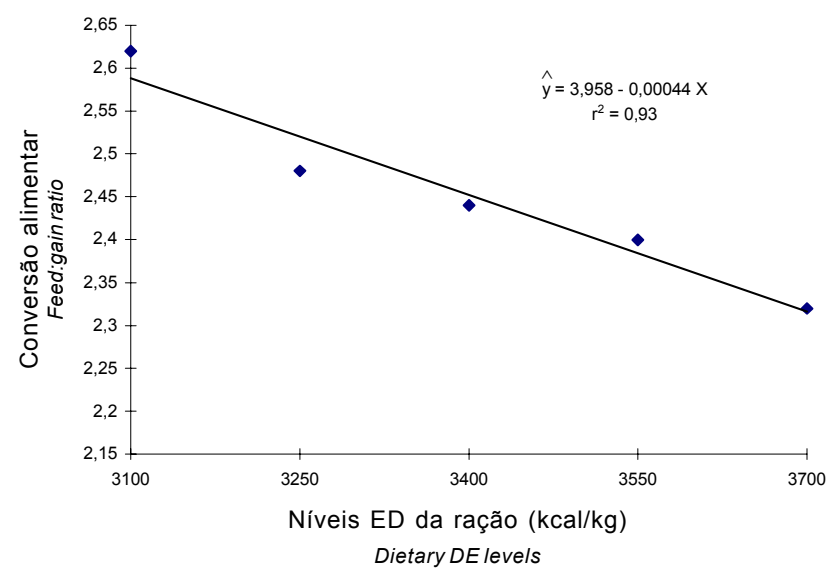

Figura 1 - Regressão da conversão alimentar em relação ao nível de ED da ração para leitoas dos 30 aos $60 \mathrm{~kg}$ em condições de conforto térmico.

Figure 1 - Regression of feed:gain ratio on the dietary $D E$ level for gilts from 30 to 60 in a thermoneutral environment.

ração. Apesar da variação ocorrida no CED de 6254 a 7133 kcal, não se observou variação significativa no GPD dos animais, indicando que, independente dos níveis de ED utilizados, a necessidade de energia digestível para ganho de peso é atendida desde que o consumo diário de ED seja de, no mínimo, $6254 \mathrm{kcal}$. De forma similar, OLIVEIRA (1996) observou variação linear no consumo de energia digestível, mas não no ganho de peso diário, de leitoas dos 15 aos $30 \mathrm{~kg}$ de peso, mantidas em ambiente termoneutro.

O consumo de proteína diário (CPD) não foi influenciado pelos níveis de ED da ração. Considerando que as rações eram isoprotéicas, a não variação significativa no consumo de ração explica o fato de o consumo de proteína não ter variado entre os tratamentos.

Os resultados obtidos de CPD indicam que o nível de proteína bruta utilizado nas rações não se constitui em fator limitante ao desenvolvimento dos animais. $\mathrm{O}$ fato de se ter utilizado rações com nível de proteína bruta correspondente a $110 \%$ do recomendado por ROSTAGNO et al. (1992), para suínos nessa fase de crescimento, assegurou o consumo adequado desse nutriente, mesmo para o grupo de animais que recebeu o tratamento correspondente a $3700 \mathrm{kcal}$ de ED, que apresentou redução de até 7,6\% no consumo de ração em relação aos demais tratamentos.

Não foi verificada variação na taxa de deposição de proteína (TDP) na carcaça, devido ao nível de ED da ração. No entanto, a menor TDP observada no nível de $3700 \mathrm{kcal}$ de ED, provavelmente, esteja relacionada ao menor consumo de proteína bruta. Resultados similares foram verificados por OLIVEIRA (1996) para leitoas dos 15 aos $30 \mathrm{~kg}$.

A taxa de deposição de gordura na carcaça (TDG) foi influenciada $(\mathrm{P}<0,05)$ pelos níveis de ED da ração, aumentando até o nível estimado de $3578 \mathrm{kcal}$ de ED de acordo com a equação $\hat{\mathrm{Y}}=-3983,24+$ $2,35586 \mathrm{X}-0,000329055 \mathrm{X}^{2}$ (Figura 2). Estes resultados evidenciam que a variação nos valores de TDG na carcaça refletiu a diferença de consumo de ED ocorrida entre os tratamentos.

Diversos autores (CAMPBELL et al., 1983; CAMPBELL E DUNKIN, 1983; GREEF et al., 1994; e OLIVEIRA, 1996) constataram aumento da deposição de gordura na carcaça de suínos associado com o de consumo de energia. Segundo SPEER (1991), o consumo diário de ração com alto teor em energia contribui para maior deposição de gordura, estando esse aumento relacionado à eficiência de síntese ou deposição de gordura na carcaça, devido ao baixo incremento calórico de dietas contendo gordura.

Analisando os dados de deposição de proteína e gordura na carcaça, constatou-se que, enquanto a TDG aumentou até o nível de $3550 \mathrm{kcal}$ de ED, a TDP não variou significativamente, entre os tratamentos. Com base nestes resultados, pode-se inferir que os níveis de ED na ração, apesar de não ter influencido o ganho de peso, propiciaram variação na ingestão de ED, que por

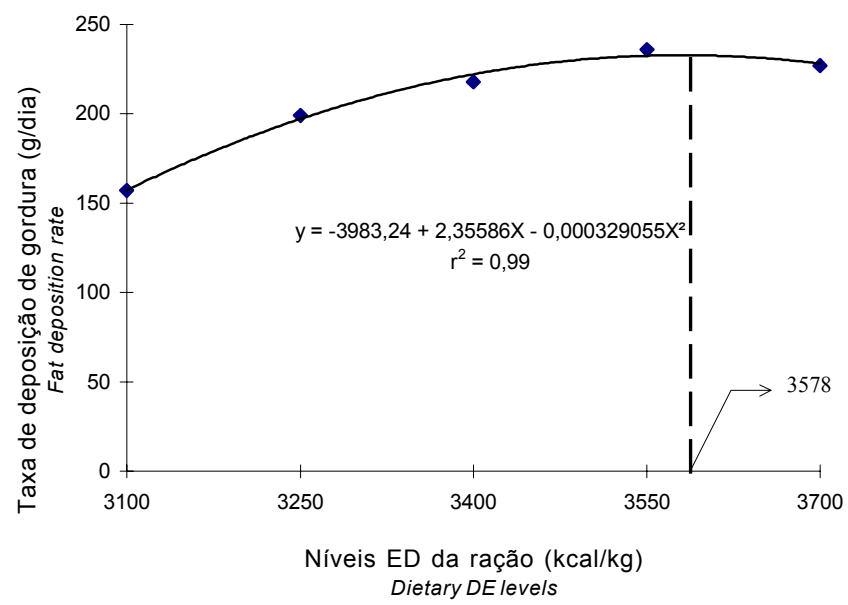

Figura 2 - Regressão de taxa de deposição de gordura em relação ao nível de ED da ração para leitoas dos 30 aos $60 \mathrm{~kg}$ em condições de conforto térmico.

Figure 2 - Regression of fat deposition rate on the dietary DE level for gilts from 30 to $40 \mathrm{~kg}$ in a thermoneutral environment. 
sua vez influenciou a composição do ganho dos animais.

\section{Experimento 2}

Os resultados de desempenho, consumos de energia digestível e proteína bruta e taxas de deposição de proteína e gordura na carcaça de suínos machos castrados são apresentados na Tabela 3. Não se observou efeito $(\mathrm{P}>0,05)$ dos níveis de energia digestível (ED) sobre o ganho de peso diário (GPD). Entretanto, constatou-se que os animais que receberam a ração com $3550 \mathrm{kcal}$ de ED apresentaram aumento, não significativo, de 3,35 a 9,47\% no GPD em relação aos daqueles verificados nos demais tratamentos. Estes resultados foram similares aos obtidos por STAHLY e CROMWELL (1979) e OLIVEIRA et al. (1997), que também não verificaram variação no ganho de peso dos suínos, em razão do aumento do nível de energia da ração.

O nível de ED da dieta influenciou o consumo de ração diário $(\mathrm{CR})$, que reduziu de forma linear $(\mathrm{P}<0,02)$ conforme a equação $\hat{Y}=4097,77-0,566533 X$ (Figura 3). A redução verificada no consumo de ração, em virtude do aumento do nível de ED, está em acordo com os relatos de diversos autores (DIVIDICH e NOBLET, 1986; DIVIDICH et al., 1987; SCHENCK et al., 1992; e OLIVEIRA et al., 1997) de que, sob condições de termoneutralidade, os suínos consomem alimentos para atender as suas necessidades de energia para mantença e crescimento.
Assim como o CR, a conversão alimentar (CA) também reduziu de forma linear $(\mathrm{P}<0,02)$, segundo a equação $\hat{Y}=5,09307-0,000774667 X$ (Figura 4), evidenciando que ocorreu melhoria da eficiência de utilização do alimento com o aumento do nível de ED da ração, o que proporcionou resultados similares de GPD nos diferentes tratamentos, apesar da diferença

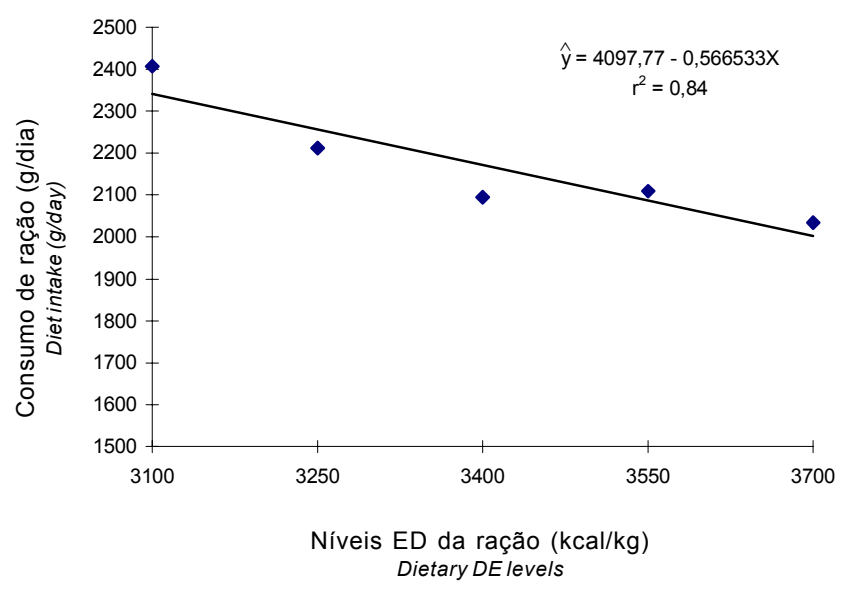

Figura 3 - Regressão do consumo de ração em relação nível de ED da ração de machos castrados dos 30 aos $60 \mathrm{~kg}$ PV de condições de conforto térmico.

Figure 3 - Regression of diet intake on the dietary $D E$ level for barrows from 30 to $60 \mathrm{~kg} \mathrm{LW}$ in a thermoneutral environment.

Tabela 3 - Desempenho, consumo de energia digestível e proteína e taxa de deposição de proteína e gordura de suínos machos castrados dos 30 aos $60 \mathrm{~kg}$ de peso consumindo rações com níveis crescentes de energia digestível sob condição de termoneutralidade

Table 3 - Performance, intake of digestible energy and protein, and rate deposition of protein and fat in barrows from 30 to $60 \mathrm{~kg}$ fed diets with increasing levels of energy in a thermoneutral environment

\begin{tabular}{|c|c|c|c|c|c|c|}
\hline \multirow[t]{2}{*}{ Item } & \multicolumn{5}{|c|}{$\begin{array}{l}\text { Nível de energia digestível (kcal/kg) } \\
\text { Digestible energylevel }\end{array}$} & \multirow[t]{2}{*}{$\mathrm{CV}$} \\
\hline & 3100 & 3250 & 3400 & 3550 & 3700 & \\
\hline $\begin{array}{l}\text { Ganho de peso } \\
\text { Weight gain }\end{array}$ & 879 & 877 & 845 & 925 & 895 & 7,4 \\
\hline $\begin{array}{l}\text { Consumo de ração } \\
\text { Feed intake }\end{array}$ & 2408 & 2212 & 2094 & 2110 & 2034 & 9,5 \\
\hline $\begin{array}{l}\text { Conversão alimentar }{ }^{2} \\
\text { Feed:gain ratio }\end{array}$ & 2,74 & 2,51 & 2,47 & 2,28 & 2,27 & 7,2 \\
\hline $\begin{array}{l}\text { Consumo de } \mathrm{ED}(\mathrm{kcal} / \mathrm{dia}) \\
\text { ED intake (kcal/day) }\end{array}$ & 7464 & 7189 & 7121 & 7491 & 7524 & 9,4 \\
\hline $\begin{array}{l}\text { Consumo de proteína }{ }^{1,2} \\
\text { Protein intake } \\
\text { Taxas de deposição na car }\end{array}$ & 397 & 365 & 346 & 348 & 336 & 9,5 \\
\hline $\begin{array}{l}\text { Carcass deposition rate } \\
\text { Proteína }{ }^{1} \\
\text { Protein }\end{array}$ & 81,45 & 82,47 & 80,45 & 81,55 & 80,44 & 9,3 \\
\hline $\begin{array}{l}\text { Gordura } \\
\text { Fat }\end{array}$ & 216,87 & 226,95 & 231,83 & 250,46 & 259,92 & 17,6 \\
\hline
\end{tabular}




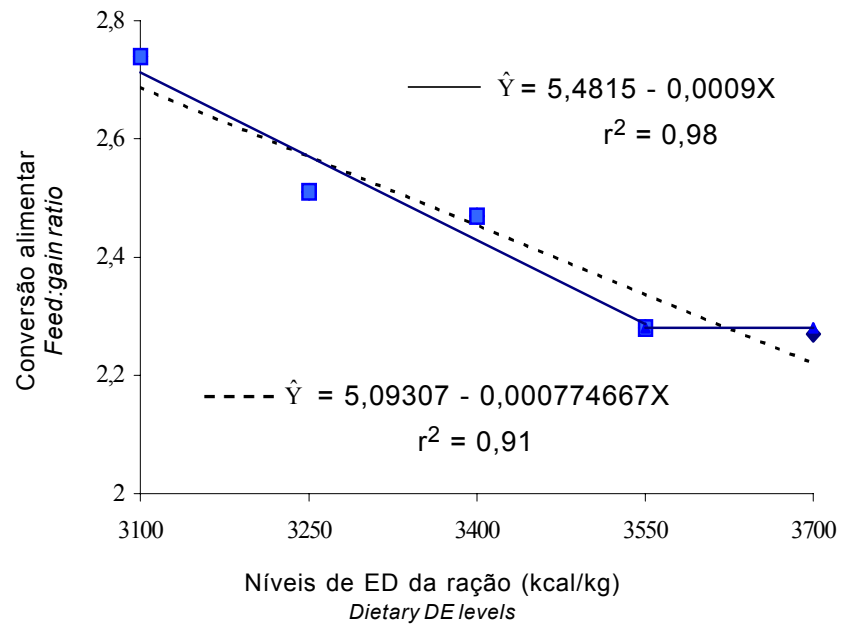

Figura 4 - Regressão da conversão alimentar em relação ao nível de ED da ração sobre a conversão alimentar de machos castrados dos 30 aos $60 \mathrm{~kg}$ em condições de conforto térmico.

Figure 4 - Regression of feed:gain ratio on the dietary $D E$ level of barrows from 30 to $60 \mathrm{~kg}$ in a thermoneutral environment.

no CR. A redução no consumo de ração e o possível aumento da energia líquida das rações, devido à inclusão de níveis crescentes de óleo de soja às rações, foram fatores que contribuíram para os resultados de CA.

Embora a CA tenha variado de forma linear, o modelo "Linear Response Plateau" - LRP, foi o que melhor se ajustou aos dados, estimando em $3582 \mathrm{kcal}$ de ED o nível a partir do qual os dados permaneceram em um platô.

Estes resultados corroboram os obtidos por STAHLY e CROMWELL (1979) e OLIVEIRA et al. (1997), que verificaram melhoria na CA de suínos de 24 a $93 \mathrm{~kg}$ e de leitões de 15 aos $30 \mathrm{~kg}$, respectivamente, em razão do aumento da densidade energética da ração, obtida pela inclusão de gordura, em ambiente termoneutro.

Apesar da redução linear observada no consumo de ração, o consumo de energia digestível diário (CED) não variou $(\mathrm{P}>0,05)$ em razão dos níveis de $\mathrm{ED}$ da ração, o que está de acordo com os resultados de DIVIDICH et al. (1987), que trabalhando com suínos machos castrados em crescimento e terminação, constataram que os animais ajustaram a quantidade de alimentos consumidos para atender as exigências nutricionais em energia, no ambiente termoneutro.

Foi verificado efeito do nível de ED da ração $(\mathrm{P}<0,02)$ sobre o consumo de proteína diário (CPD), que reduziu de forma linear, conforme a equação $\hat{\mathrm{Y}}=676,133-0,0934780 X$. Esta redução linear de CPD está diretamente relacionada com a do consu- mo, uma vez que as rações eram isoprotéicas.

Mesmo ocorrendo redução no consumo de proteína, não se constatou variação na taxa de deposição de proteína na carcaça (TDP) dos animais. Corroborando esses dados, NOBLET et al. (1985) e DIVIDICH et al. (1987) também não verificaram variação na retenção de proteína na carcaça de suínos machos castrados em crescimento devido ao aumento de energia da ração. Já OLIVEIRA et al. (1997) encontrou efeito quadrático dos níveis de ED das rações sobre a TDP na carcaça de leitões castrados dos 15 aos $30 \mathrm{~kg}$, mantidos em ambiente termoneutro.

Comparando os dados de consumo de proteína com os de TDP na carcaça, pode-se deduzir que a não variação na TDP está relacionada ao fato de que, provavelmente, a capacidade genética de retenção de nitrogênio na carcaça desses animais foi atingida no menor consumo de proteína de $336 \mathrm{~g} /$ dia.

A taxa de deposição de gordura (TDG) foi linearmente influenciada pelo nível de ED das rações, conforme a equação $\hat{Y}=-11,6124+0,0732721 \mathrm{X}$ (Figura 5). Apesar de os tratamentos em que se utilizaram os níveis de 3100,3550 e $3700 \mathrm{kcal}$ de ED terem apresentado pequena variação no consumo de ED, as TDG na carcaça nos tratamentos correspondentes a 3550 e $3750 \mathrm{kcal}$ foram, respectivamente, 15,49 e 19,85\% superiores à verificada no nível de

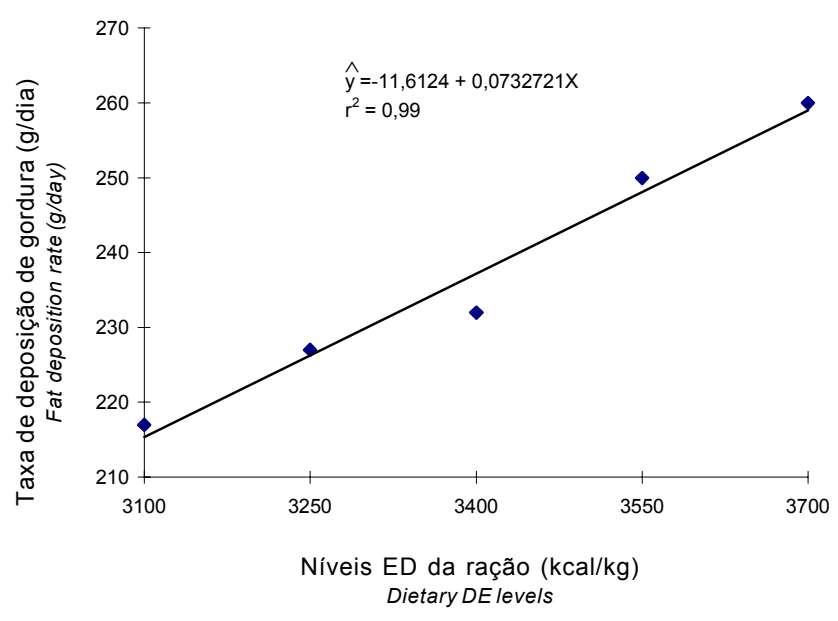

Figura 5 - Regressão da deposição de gordura em relação ao nível de ED da ração de machos castrados dos 30 aos $60 \mathrm{~kg}$ de peso em condições de conforto térmico.

Figure 5 - Regression of the fat deposition rate on the dietary $D E$ level for barrows from 30 to $60 \mathrm{~kg}$ in a thermoneutral environment. 
$3100 \mathrm{kcal}$ de ED. Os aumentos da TDG verificados nos níveis mais altos de ED podem ser explicados pelo possível aumento da energia líquida das rações com 3550 e $3700 \mathrm{kcal}$ de ED e pelos resultados de consumo de proteína que sugerem que os animais do tratamento de $3100 \mathrm{kcal}$ utilizaram energia para o catabolismo de excesso de proteína consumido, tendo como conseqüência a redução na TDG da carcaça.

Segundo SCHOENHERR et al. (1987), a energia derivada da gordura é mais eficientemente utilizada para retenção de energia em proteína e gordura que a de uma ração à base de milho e soja, em ambiente termoneutro. SPEER (1991) relatou que a adição de gordura à dieta aumenta a eficiência de utilização da energia e a deposição de gordura na carcaça. Esta maior deposição de gordura está relacionada à eficiência de síntese ou de deposição de gordura derivada da gordura da dieta, associada ao reduzido incremento calórico da gordura.

\section{Conclusões}

As rações com energia digestível entre $3250 \mathrm{e}$ $3700 \mathrm{kcal} / \mathrm{kg}$ de ração, para leitoas de 30 a $60 \mathrm{~kg}$, propiciaram semelhantes resultados de ganho de peso, e o nível de $3700 \mathrm{kcal}$ de ED, em que o óleo contribuiu com $20,9 \%$ da ED total, proporcionou os melhores resultados de CA.

A ração com o nível estimado de $3582 \mathrm{kcal}$ de ED $/ \mathrm{kg}$ de ração, no qual o óleo contribuiu com $15,7 \%$ da ED total, proporcionou os melhores resultados de conversão alimentar de suínos machos castrados de 30 a $60 \mathrm{~kg}$ de peso mantidos em ambiente de termoneutralidade.

\section{Referências Bibliográficas}

CAMPBELL, R.G., DUNKIN, A.C. 1983. The influence of dietary protein and energy intake on the performance, body composition and energy utilization of pigs growing from $7 \mathrm{a}$ 19 kg. Anim. Prod., 36:185-192.

CAMPBELL, R.G., TAVERNER, M.R., CURIC, D.M. 1983. The influence of feeding level from 20 to $45 \mathrm{~kg}$ live weight on the performance and body composition of female and entire male pigs. Anim. Prod., 36:193-199.

DIVIDICH, J.L., NOBLET, J. 1986. Effect of dietary energy level on the performance of individually housed early-weaned piglets in relation to environmental temperature. Lvstck. Prod. Sci., 14:255-263.

DIVIDICH, J.L., NOBLET, J., BIKAWA, T. 1987. Effect of environmental temperature end dietary energy concentration on the performance and carcass characteristics of growingfinishing pigs fed to equal rate of gain. Lvstck. Prod. Sci., $17: 235-246$
NOBLET, J., DIVIDICH, J.L., BIKAWA, T. 1985. Interaction between energy level in the diet and environmental temperature on the utilization of energy in growing pigs. J. Anim. Sci., 61(2):452-459.

OLIVEIRA, R.F.M. Efeito do nível de energia digestivel e da temperatura ambiente sobre o desempenho e sobre os parâmetros fisiológicos e hormonal de suínos dos 15 aos 30 kg. Viçosa, MG: UFV, 1996. 150p. Tese (Doutorado em Zootecnia) - Universidade Federal de Viçosa.

OLIVEIRA, R.F.M., DONZELE, J.L., FREITAS, R.T.F. et al. 1997. Níveis de energia digestível para leitões dos 15 aos 30 $\mathrm{kg}$ de peso mantidos em ambiente de conforto térmico. $R$. Bras. Zootec., 26(03):539-547.

PETTIGREW, J.E., MOSER, R.L.1991. Fat in swine nutrition. In: MILLER, E.R., ULLREY, E.D., LEWIS, A.J. (Eds.) Swine nutrition. Butterworth-Heinemann. p. 133-145.

ROSTAGNO, H.S., SILVA, D.J. et al. 1992. Composição de alimentos e exigências nutricionais de aves e suínos (Tabelas Brasileiras). Viçosa, MG: UFV, Impr. Univ., 59 p.

SCHENCK, B.C., STAHLY, T.S., CROMWELL, G.L. 1992. Interactive effects of thermal environmental and dietary lisine and fat levels on rate, efficiency, and composition of growth of weanling pigs. J. Anim. Sci., 70:3791-3802.

SCHOENHERR, T.S., STAHLY, T.S., CROMWELL, G.L. 1987. Effects of environmental temperature and dietary fat additions on maintenance and partial efficiency retention in growing swine. J. Anim. Sci., 65:122, (supplement 1).

SILVA, D.J. 1990. Análise de alimentos (Métodos químicos e biológicos). Viçosa - MG: UFV, Impr. Univ. 166p.

SPEER, V.C.1991. Maximizing lean tissue growth: genetic, nutritional, and environmental factors. In: MILLER, E.R., ULLREY, E.D., LEWIS, A.J. Swine nutrition. ButterworthHeinemann. p. 91-102.

STAHLY, T.S., CROMWELL, G.L. 1979. Effect of environmental temperature and dietary fat supplementation on the performance and carcass characteristics of growing and finishing swine. J. Anim. Sci., 49(6):1478-1488.

VERSTEGEN, M.W.A, CLOSE, W.H. 1994. The environment and the growing pig. In: COLE, D.J.A., WISEMAN, J., VARLEY, M.A. (Eds.) Principles of pig science. Longhborough: Nothingan University Press. p.333-353.
Recebido em: 22/04/98 Aceito em: 20/11/98 